\title{
Tricyanovinylpyrroles: synthesis, conformational structure, photosensitizing properties, and electrical conductivity
}

\author{
Boris A. Trofimov, * Lubov' N. Sobenina, Andrey P. Demenev, Al'bina I. Mikhaleva, Igor' \\ A. Ushakov, Ol'ga A. Tarasova, Vladimir I. Smirnov, Konstantin B. Petrushenko, \\ Alexander I. Vokin, Natal'ya M. Murzina, and Galina F. Myachina
}

A.E. Favorsky Institute of Chemistry, Siberian Branch of the Russian Academy of Sciences, Russ664033 Irkutsk, 1 Favorsky, Russia

E-mail: bat@irioch.irk.ru

\begin{abstract}
Dedicated to academician M. G. Voronkov's $80^{\text {th }}$ birthday
(received 28 Feb 01; accepted 31 Dec 00; published on the web 08 Jan 01)
\end{abstract}

\begin{abstract}
5-Alkyl- and 5-phenyl-substituted 2-methyl-1H-pyrroles reacting with tetracyanoethylene selectively formed of 3-(1,2,2-tricyanovinyl)pyrroles in high yields. 2-Methyl-5-(2-thienyl)-1Hpyrrole gave mixtures of 3- and 4-(1,2,2-tricyanovinyl)pyrroles (ratio 5:1). The main reaction of 2-(2-furyl)-5-methyl-1H-pyrrole with tetracyanoethylene involves attack of the 2-position of the furan ring. $A b$ initio calculations $\left(\mathrm{HF} / 6-31 \mathrm{G}^{*}\right)$ were performed to clarify the equilibrium conformation of the synthesized compounds. The photosensitizing properties and electrical conductivity were studied.
\end{abstract}

Keywords: Pyrroles, tetracyanoethylene, (1,2,2-tricyanovinyl)pyrroles, conformational structure, photosensitizing properties, electrical conductivity

\section{Introduction}

Tricyanovinyl derivatives of heterocyclic compounds are of great interest both as molecular systems having high charge-transfer ability in the electronic ground state, and as promising conductive organic materials.

Previously, it has been shown that 2-unsubstituted pyrroles but with substituents in other ring positions react readily and selectively with tetracyanoethylene (TCNE) to form 2-(1,2,2tricyanovinyl)pyrroles in high yield. ${ }^{1,2}$ The reaction of 2,5-disubstituted pyrroles with TCNE

leading to 3-(1,2,2-tricyanovinyl)pyrrole has been reported only for 2,5-dimethylpyrrole. ${ }^{3}$ Extending this study, we carried out the reaction of 2,3,5-trisubstituted pyrroles 1a-c and 2,5disubstituted pyrroles 3d,e with TCNE and synthesized the corresponding 3- and 4-(1,2,2- 
tricyanovinyl)-substituted pyrroles $\mathbf{2 a}-\mathbf{c}, \mathbf{4 d}, \mathbf{5 e}$ and $\mathbf{4 e}, \mathbf{5 d}$, respectively.

\section{Results and Discussion}

\section{Synthesis}

Tricyanovinylation was carried out in DMSO at room temperature within $30 \mathrm{~min}$. Under these conditions pyrroles 1a-c reacted with TCNE regioselectively forming 3-tricyanovinyl derivatives 2a-c in 85-94\% yield (Scheme 1).

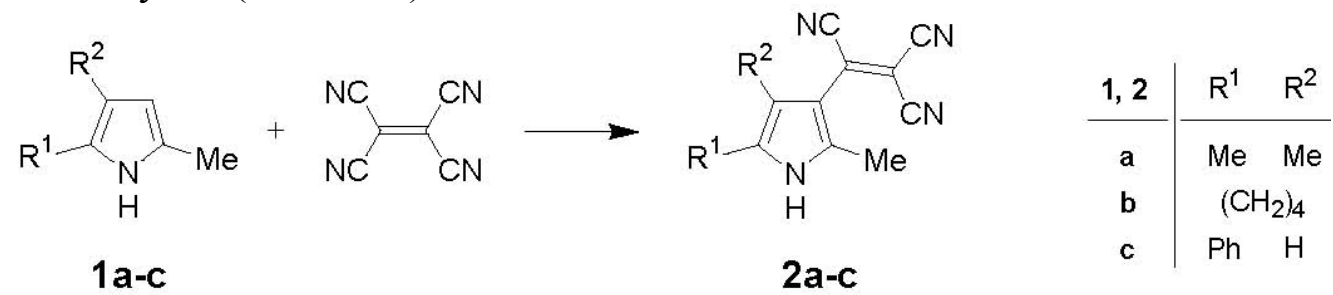

\section{Scheme 1}

The structure of 3-(1,2,2-tricyanovinyl)-2-methyl-5-phenylpyrrole (2c) is based on NMR data. The formation of the possible isomer 4-(1,2,2-tricyanovinyl)-2-methyl-5-phenyl-pyrrole seems to be sterically prevented by the 5 -phenyl substituent.

In 2-methyl-5-(2-thienyl)-1H-pyrrole (3d) and 2-(2-furyl)-5-methyl-1H-pyrrole (3e) the presence of two five-membered heteroaromatic rings prone to tricyanovinylation made the reaction with TCNE intriguing (Scheme 2).

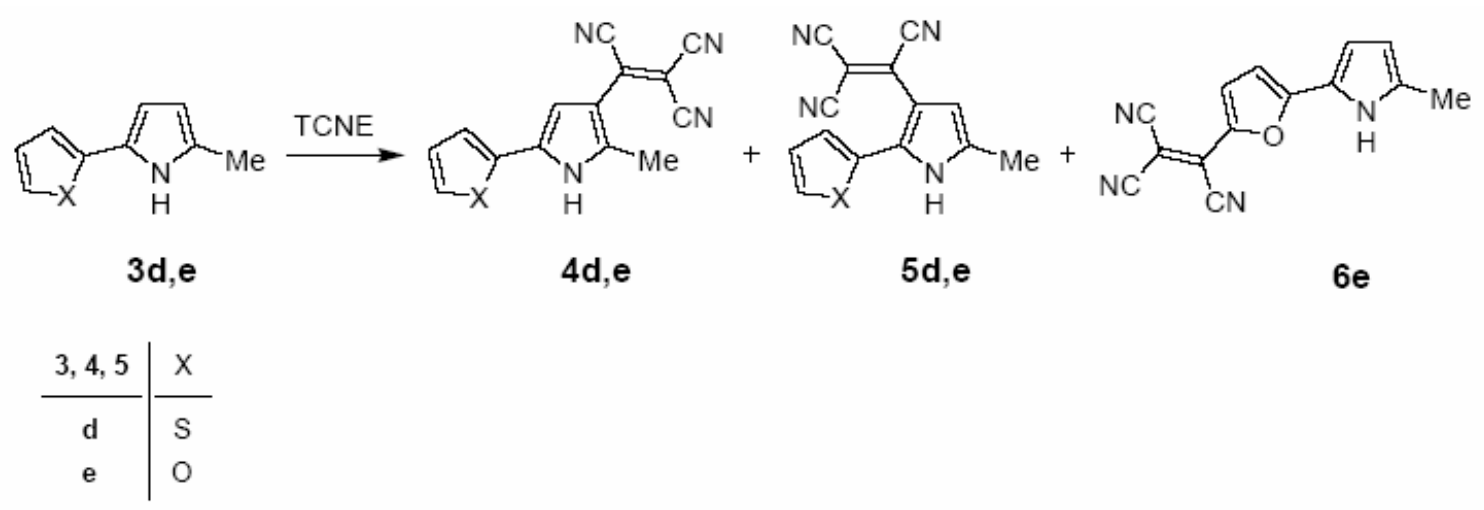

\section{Scheme 2}

According to an earlier report, ${ }^{4}$ the pyrrole nitrogen atom has a better ability to delocalize the positive charge of $\sigma$-complexes as compared to the oxygen atom in furan or the sulfur atom in thiophene; thus, pyrrole is considerably more reactive towards electrophilic substitution than furan and even more reactive than thiophene. Accordingly, trifluoroacetylation of 2-(2-furyl)and 2-(2-thienyl)pyrroles with trifluoroacetic anhydride proceeded selectively to form the corresponding 5-trifluoroacetyl-substituted pyrroles; although under the same conditions 2-(2- 
furyl)-1-vinylpyrrole is selectively acetylated at the furan ring. ${ }^{5-7}$

2-Methyl-5-(2-thienyl)pyrrole (3d) reacted with TCNE forming only products of pyrrole ring tricyanovinylation (Scheme 2): Apart from the 3-tricyanovinyl derivative 4d the 4-tricyanovinyl isomer 5d was formed as well (total yield 90\%, isomer ratio $4 \mathbf{d} / \mathbf{5 d}$ 5:1).

5-Methyl-2-(2-furyl)pyrrole (3e) behaved quite differently in this reaction: The main reaction product 6e results from the substitution at the 2-position of the furan ring; in addition, also the 4and 3-tricyanovinyl-substituted pyrrole derivatives $\mathbf{4 e}$ and $\mathbf{5 e}$, respectively, were isolated [ratio $\mathbf{6 e} /(\mathbf{4 e}+\mathbf{5 e}) 3: 1]$. The ratio of the tricyanovinylation products at the furan ring $\alpha$-position and the pyrrole ring $\beta$-positions is $3: 1$.

In interpreting these results it seems reasonable to take into account the considerably greater nucleophilicity of the furan ring as compared with that of the thiophene ring and the possible steric influence of the 5-methyl group impeding the substitution at the $\beta$-positions of the pyrrole ring. The reactivity of the thiophene ring is low compared with that of the furan ring and even lower than that of the pyrrole ring; therefore, this factor does not seem strong enough to affect the direction of the reaction with 5-(2-thienyl)pyrrole. The absence of products of double tricyanovinylation points to a very strong deactivating effect of the tricyanovinyl group that is transmitted from the pyrrole ring to the furan and thiophene rings.

The introduction of an $N$-vinyl or $N$-isopropenyl group in $7 \mathbf{f}$ and $\mathbf{7 g}$, respectively, gives rise only to 3-tricyanovinyl substitution products 8f,g (yields 92 and 91\%, respectively; Scheme 3). A characteristic reaction of $N$-vinylheterocycles is the [2+2] cycloaddition reaction leading to the formation of cyclobutane derivatives of type 98,9 (a product of this type has been obtained in the reaction of $\mathrm{N}$-vinyl-4,5,6,7-tetrahydroindole with TCNE in benzene10), but this was not observed in the reaction of $\mathbf{7 f}$ and $\mathbf{7 g}$.

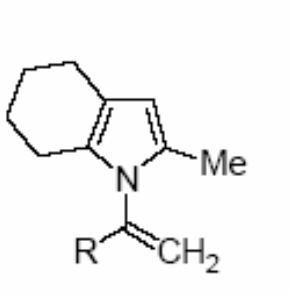

$7 f, g$

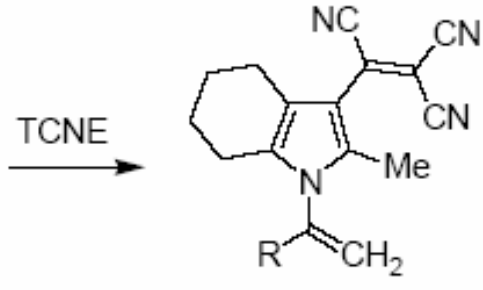

$8 f, g$

\begin{tabular}{c|l}
$7,8,9$ & $\mathrm{X}$ \\
\hline $\mathrm{f}$ & $\mathrm{H}$ \\
$\mathrm{g}$ & $\mathrm{Me}$
\end{tabular}

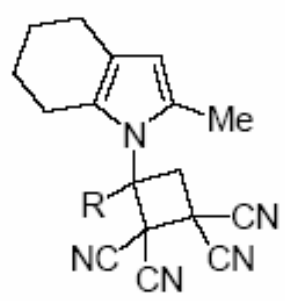

9

\section{Scheme 3}

\section{Structures}

The synthesized products are colored: bright dark-cherry $(\mathbf{2 a}-\mathbf{c}, \mathbf{8 f}, \mathbf{g})$ or black-blue $(\mathbf{4 d}, \mathbf{e}, \mathbf{5 d}, \mathbf{e}$, 6e) crystals with metal luster. The structure and composition have been proved by IR and NMR spectroscopy and by elemental analysis.

The IR spectra of all the compounds show an intense band in the $2213-2229 \mathrm{~cm}^{-1}$ region, corresponding to the nitrile group vibration. The $\mathrm{C}=\mathrm{C}$ bond vibrations of the $\mathrm{C}$-olefinic substituents are of low intensity and can be identified only with difficulty. The intense bands in 
the 3266-3351 $\mathrm{cm}^{-1}$ region of the pyrroles $\mathbf{2 a}-\mathbf{c}, \mathbf{4 d}, \mathbf{e}, \mathbf{5 d}, \mathbf{e}, \mathbf{6 e}$ correspond to the $\mathrm{NH}$ group vibrations. The $\mathrm{C}=\mathrm{C}$ stretching vibrations of $N$-vinyl and $N$-isopropenyl groups of $\mathbf{8 f}$ and $\mathbf{8 g}$ are observed at 1644 and $1666 \mathrm{~cm}^{-1}$, respectively.

The assignment of the ${ }^{1} \mathrm{H}$ NMR signals is based on the analysis of 2D spectra of correlation spectroscopy (COSY) and 2D Nuclear Overhauser Effect Spectroscopy (NOESY).

The analysis of 2D NOESY spectra made it possible to reliably distinguish between the isomers of compounds $\mathbf{4 d}$ and $\mathbf{5 d}, \mathbf{4 e}$ and $\mathbf{5 e}$, and to confirm the structure of compound $\mathbf{2 c}$. Thus, in the spectrum of compound $\mathbf{4 d}$ a nuclear Overhauser effect can be observed for the pyrrole ring $\mathrm{H}-4$ proton with the thiophene ring H-3 proton; this effect is absent for the pyrrole ring proton with the 2-methyl group. This allows the unambiguous determination of the position of the tricyanovinyl group in this compound. On the contrary, the 2D NOESY spectrum of compound 5d shows a cross peak of the pyrrole ring H-3 with the 2-methyl group but there is no cross-peak of the pyrrole ring proton with the thiophene ring proton; this is taken as evidence for the attachment of the tricyanovinyl group at ring position 4 . The $2 \mathrm{D}$ spectrum for compound $6 \mathbf{e}$ exhibits cross peaks of the 5-methyl group with pyrrole $\mathrm{H}-4, \mathrm{H}-3$ with $\mathrm{H}-4$, furan ring proton $\mathrm{H}-4$ with proton $\mathrm{NH}$ and furane ring H-3 with H-4 enabling the determination of the tricyanovinyl group position.

In order to clarify the equilibrium conformation of the synthesized products $a b$ initio calculations $\left(\mathrm{HF} / 6-31 \mathrm{G}^{*}\right)$ were performed with the pyrrole 2a as an example. According to the data obtained, the $\beta$-C atom of the tricyanovinyl group is significantly out of the pyrrole ring plane. The rotational isomers of compound $\mathbf{2 a}$ are labeled as syn-clinal (sc) and anti-clinal (ac) in accordance with the position of the $\beta-\mathrm{C}$ atom of the exocyclic double bond relatively the endocyclic bond (Figure 1).

The syn-clinal rotamer of compound $\mathbf{2 a}$ in the gas phase is energetically favored by 1.6 $\mathrm{kcal} / \mathrm{mol}$ over the $a c$-form. Since the $s c$ - and $a c$-conformers have practically the same dipole moments $\left(\mu 6-31 \mathrm{G}^{*}=8.28\right.$ and $\left.8.34 \mathrm{D}\right)$, in a non-hydrogen bonding solvent the $s c$-rotamer of the pyrrole 2a will be also most populated one.

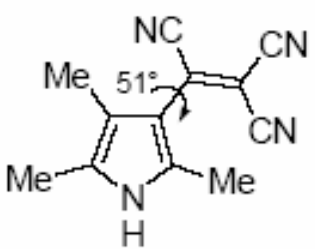

$S C$

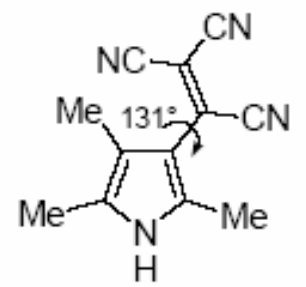

ac

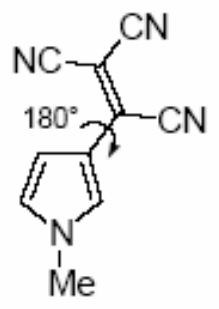

ap

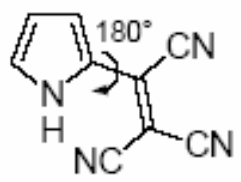

ap

2a

Figure 1. Definitions of rotamers for compounds $\mathbf{2 a}, \mathbf{1 0}, \mathbf{1 1}$, and equilibrium torsional angles for the isolated molecules from $\mathrm{HF} / 6-31 \mathrm{G}^{*}$ ab initio calculations.

X-ray diffraction data11 of 3-tricyanovinyl-1-methylpyrrole $\mathbf{1 0}$ indicate that in the solid state 
the tricyanovinyl group is coplanar with the pyrrole ring adopting the ap-conformation. Possibly, this is due to the absence of steric hindrance but may also be inferred by the physical state (like 2-phenylpyrrole12 and biphenyls13). Since the equilibrium geometry of pyrrole $\mathbf{1 0}$ in the gas phase is unknown an $a b$ initio calculation $\left(\mathrm{HF} / 6-31 \mathrm{G}^{*}\right)$ of the ap-form of 1-methyl-3tricyanovinylpyrrole has been obtained. The result suggests a planar structure, the calculated pyrrole ring bond lengths and valence angles are close to the values as measured in the crystal (deviations do not exceed $0.01 \AA$ and $0.8^{\circ}$ ) (Table 1).

Table 1. Geometry parameters of 3-(1,2,2-tricyanovinyl)-2,4,5-trimethylpyrrole (2a), 3-(1,2,2tricyanovinyl)-1-methylpyrrole (10) and 2-(1,2,2-tricyanovinyl)pyrrole (11) from ab initio calculations $\left(\mathrm{HF} / 6-31 \mathrm{G}^{*}\right)$ and X-ray diffraction

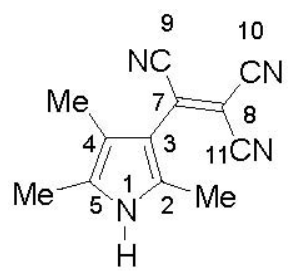

$2 a$

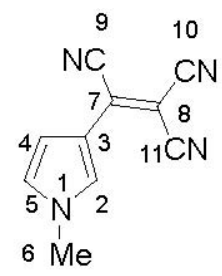

10

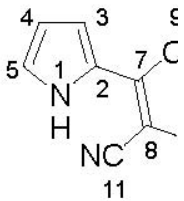

11

\begin{tabular}{|c|c|c|c|c|c|c|c|c|c|}
\hline \multirow{3}{*}{$\begin{array}{l}\text { Bond } \\
\text { length }\end{array}$} & \multicolumn{3}{|c|}{$a b$ initio } & $\begin{array}{c}\text { X- } \\
\text { Rav }^{9}\end{array}$ & \multirow{3}{*}{$\begin{array}{c}\text { Valence } \\
\text { angle }\end{array}$} & \multicolumn{3}{|c|}{$a b$ initio } & $\begin{array}{c}\text { X- } \\
\text { Rav }^{9}\end{array}$ \\
\hline & \multicolumn{4}{|c|}{$[\AA]$} & & \multicolumn{4}{|c|}{$\left[{ }^{\circ}\right]$} \\
\hline & $\mathbf{2} \mathbf{a}(a c)$ & $\mathbf{1 0}(a p)$ & $\mathbf{1 1}(a p)$ & $\mathbf{1 0}(a p)$ & & $\mathbf{2 a}(a c)$ & $10(a p)$ & $\mathbf{1 1}(a p)$ & $\mathbf{1 0}(a p)$ \\
\hline N-1,C-2 & 1.346 & 1.336 & 1.376 & 1.330 & C-5,N-1,C-2 & 111.3 & 109.0 & 109.3 & 109.1 \\
\hline $\mathrm{C}-2, \mathrm{C}-3$ & 1.373 & 1.381 & 1.382 & 1.392 & $\mathrm{~N}-1, \mathrm{C}-2, \mathrm{C}-3$ & 106.7 & 109.1 & 107.0 & 109.1 \\
\hline C-3,C-4 & 1.448 & 1.437 & 1.401 & 1.430 & C-2,C-3,C-4 & 107.9 & 106.1 & 107.8 & 106.9 \\
\hline C-4,C-5 & 1.355 & 1.349 & 1.372 & 1.354 & C-3,C-4,C-5 & 106.1 & 106.6 & 106.6 & 107.1 \\
\hline N-1,C-5 & 1.376 & 1.374 & 1.341 & 1.384 & C-4,C-5,N-1 & 107.9 & 109.2 & 109.3 & 108.6 \\
\hline N-1,C-6 & & 1.450 & & 1.468 & C-2,C-3,C-7 & 124.3 & 123.0 & & 122.2 \\
\hline C-2,C-7 & & & 1.437 & & C-3,C-7,C-8 & 126.1 & 128.9 & & 128.8 \\
\hline C-3,C-7 & 1.466 & 1.447 & & 1.430 & C-3,C-7,C-9 & 116.1 & 114.5 & & 115.9 \\
\hline C-7,C-8 & 1.344 & 1.351 & 1.356 & 1.357 & C-8,C-7,C-9 & 117.8 & 116.6 & & 115.3 \\
\hline C-7,C-9 & 1.451 & 1.453 & 1.451 & 1.460 & C-7,C- $8, C-10$ & 122.5 & 121.9 & 122.3 & 121.1 \\
\hline C- $8, C-10$ & 1.442 & 1.439 & 1.436 & 1.439 & C-7,C-8,C-11 & 122.1 & 123.1 & 122.0 & 122.4 \\
\hline C-8,C-11 & 1.440 & 1.437 & 1.435 & 1.443 & C-10,C-8,C-11 & 115.3 & 114.9 & 115.7 & 116.5 \\
\hline
\end{tabular}

Differences are mainly observed for N-1,C-6 (0.018 $\AA$ ), C-3,C-7 (0.017 $\AA$ ) bonds and C-3,C$7, \mathrm{C}-9\left(1.4^{\circ}\right), \mathrm{C}-8, \mathrm{C}-7, \mathrm{C}-9\left(1.3^{\circ}\right), \mathrm{C}-10, \mathrm{C}-8, \mathrm{C}-11\left(1.6^{\circ}\right)$ valence angles. Thus, the planar structure of $\mathbf{1 0}$ in the crystalline state does not result from any solid phase effects. The coplanarity between the pyrrole ring and the tricyanovinyl substituent enables optimal overlapping of the $\pi$ - 
bonds. Deviation from coplanarity in pyrrole 2a resembles a compromise of $\pi$-electron interaction and steric hindrance with the methyl group. The non-planar structure of the pyrrole 2a results in a significant lengthening of the C-3,C-7 bond compared to compound $\mathbf{1 0}$ (from 1.447 to $1.466 \AA$ ), some shortening (by $0.007 \AA$ ) of the $\mathrm{C}-7, \mathrm{C}-8$ bond and a $1-3^{\circ}$ change of the C-3,C-7,C-9, C-8,C-7,C-9 and C-3,C-7,C-8 valence angles. The C-3,C-7 bond elongating in going from the pyrrole 10 to compound 2a provides direct evidence for steric inhibition of $\pi$ electron interaction. This should affect not only the equilibrium geometry of the molecule, but also some characteristics of the electronic structure such as UV spectrum, charge distribution, dipole moment, single-electron ionization energy.

It was also of interest to compare the geometries of 2- and 3-tricyanovinylpyrroles $\mathbf{1 0}$ and $\mathbf{1 1}$, which are coplanar, antiperiplanar conformers with respect to the endo- and exocyclic double bonds (Figure 1). The tricyanovinyl group geometry is practically the same in both isomers $\mathbf{1 0}$ and 11 (Table 1). On the other hand, the ap-conformers of compounds $\mathbf{1 0}$ and $\mathbf{1 1}$ differ in pyrrole ring geometry and interfragmental bond length, which is shorter in 2-(1,2,2-tricyanovinyl)pyrrole 11. This suggests some contribution of the zwitterionic mesomeric structures to the electronic ground states of compounds $\mathbf{1 0}$ and $\mathbf{1 1}$ (Figure 2).

In line with this simplified approach, the excess of electron density $(0.25 \mathrm{e}$ for both compounds) is indeed concentrated on the tricyanovinyl group atoms as suggested by ab initio calculations of charge distribution in the ground state. Furthermore, since in the charge separated resonance structure of $\mathbf{1 0}$ the length of dipole is significantly longer than in the corresponding one of 11, it may be expected that the dipole moment of the ap-conformer of compound $\mathbf{1 0}$ will be larger than in the ap-form of molecule 11. The contribution of zwitterionic resonance structures should be reflected by large dipole moments, and this was confirmed by calculations (9.76 and 7.00 D for the ap-forms of $\mathbf{1 0}$ and 11, respectively).

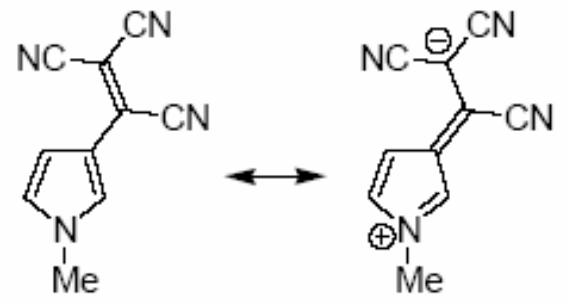

10

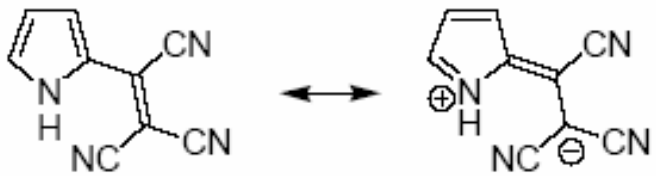

11

Figure 2. Zwitterionic resonance structures of compounds 10 and 11.

It was established that 3-(1,2,2-tricyanovinyl)-2-methyl-5-phenylpyrrole (2c), 3-(1,2,2tricyanovinyl)-2-methyl-5-(2-thienyl)pyrrole (4d) and the earlier prepared ${ }^{2}$ 2-(1,2,2tricyanovinyl)-5-phenylpyrrole (12) possess sensitizing properties with respect to polymeric photoconductors. This is illustrated by some data for poly-9-vinylcarbazole (PVCz) sensitized by compounds (2c), (4d), (12) (Figure 3). Their good solubility and compatibility with PVCz makes it possible to vary the concentration in the photoconductor layer over a range of $0.5-40 \%$, and 
this gives a chance to create photosensitive layers with different luminous transmission. Reasonably high concentrations of compounds 2c, 4d and $\mathbf{1 2}$ do not affect the electric parameters of layers, as is the case with most dyes used as sensitizers. The induction surface potential $\left(\mathrm{U}_{0}=+300 \mathrm{~V}\right)$ and its dark half-drop time $\left(\tau_{0.5}=330-300 \mathrm{sec}\right)$ are in agreement with the corresponding values for individual layers of the polymeric photoconductor ( $\mathrm{PVCz})$. $\mathrm{S}_{0.5}, \mathrm{~m}^{2} \cdot \mathrm{J}^{-1}$

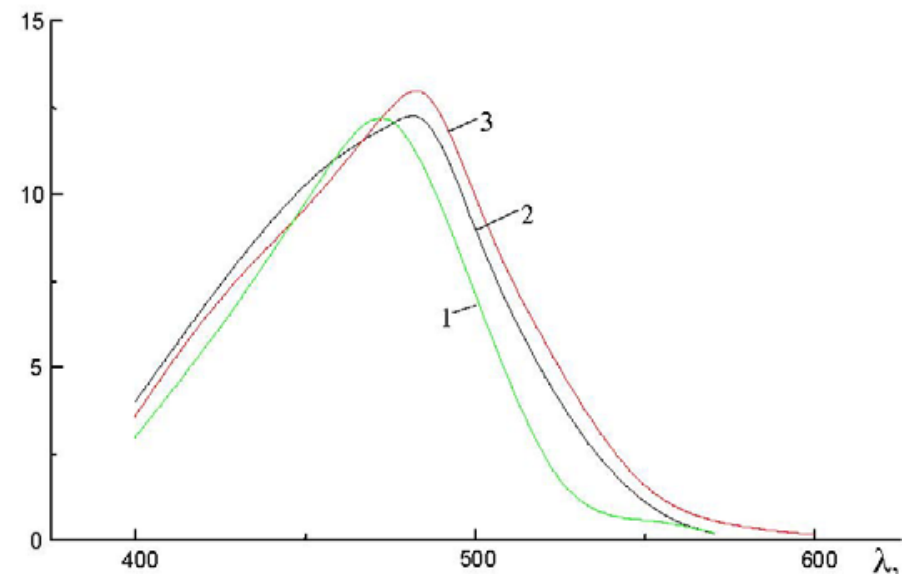

Figure 3. Photoconductivity spectra of sensitized PVCz layers: 1 - pyrrole 2c, 2 - pyrrole 4d, 3 pyrrole 12.

The dependence of electrophotographic sensitivity $\left(\mathrm{S}_{0.5}, \mathrm{~m} 2 \cdot \mathrm{J}-1\right)$ on concentration $(\mathrm{C}$, mas.\%), for sensitizers $\mathbf{2 c}, \mathbf{4 d}, \mathbf{1 2}$ in a PVCz layer is presented in Table 2 for a maximum of the photoconductivity spectral distribution of these compounds. The results show the optimal concentration to be 10-15 mas.\%. The introduction of 40 mas.\% and more of sensitizer into the polymer leads to a fast decrease in the induced surface potential $\mathrm{U}_{0}$ and, as a consequence, reduces electrophotographic sensitivity.

Table 2. Electrophotographic sensitivity $\left(\mathrm{S}_{0,5}, \mathrm{~m}_{2} \cdot \mathrm{J}_{-1}\right)$ at different concentrations of $\mathbf{2 c}, \mathbf{4 d}, \mathbf{1 2}$

\begin{tabular}{cccc}
\hline C, mas. \% & 2c & 4d & $\mathbf{1 2}$ \\
\hline 0.5 & 1.6 & 1.8 & 2.0 \\
5 & 6.7 & 7.4 & 8.1 \\
10 & 11.8 & 12.3 & 13.0 \\
15 & 9.4 & 11.6 & 12.5 \\
20 & 5.9 & 7.0 & 7.5 \\
30 & 3.2 & 3.3 & 3.6 \\
40 & fast decay $\mathrm{U}_{o}$ & fast decay $\mathrm{U}_{o}$ & fast decay $\mathrm{U}_{\mathrm{o}}$ \\
\hline
\end{tabular}

The spectral distribution of photoconductivity (Figure 3) in the visible region gives rise to the sensitizer electron absorption band related to intramolecular charge transfer from the pyrrole ring 
nitrogen atom onto the terminal $\mathrm{CN}$ group of the tricyanovinyl group with the formation of polar structures (Scheme 4).<smiles>[R]c1cc(C(C#N)=C(C#N)C#N)c(C)n1C</smiles>

$2 \mathrm{c} R=\mathrm{Ph}$

4d $R=2$-thienyl

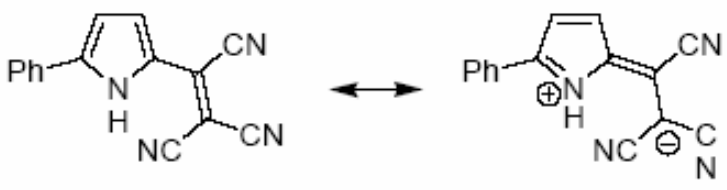

12

\section{Figure 4}

The possible existence of polar structures of this kind is evidenced by the observed bathochromic shift of the absorption band maximum of intramolecular charge transfer in going from compound $2 \mathrm{c}, \lambda=475 \mathrm{~nm}$, to compound $\mathbf{1}, \lambda=489 \mathrm{~nm}$ (Figure 5). An increase in the number of double bonds of the conjugated system responsible for intramolecular charge transfer should determine the band maximum shift in electron absorption spectra as actually found $(\Delta \lambda=$ $14 \mathrm{~nm})$.

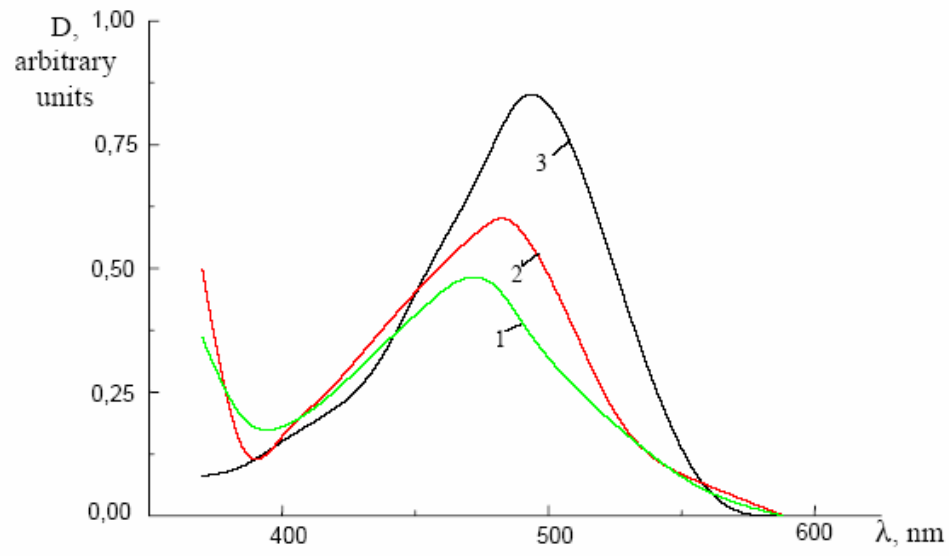

Figure 5. Electron absorption spectra: 1 - pyrrole 2c, 2 - pyrrole 4d, 3 - pyrrole 12.

Table 3. Electric conductivity $(\sigma, \mathrm{Cm} \cdot \mathrm{cm}-1)$ of pyrroles $\mathbf{2 b}, \mathbf{2 c}, \mathbf{4 d}, \mathbf{6 e}$

Compound Electric conductivity

(films)

\begin{tabular}{cc}
\hline $\mathbf{2 b}$ & $1.8 \cdot 10^{-13}$ \\
$\mathbf{2 c}$ & $2.3 \cdot 10^{-9}$ \\
$\mathbf{4 d}$ & $3.3 \cdot 10^{-12}$ \\
$\mathbf{6 e}$ & $2.8 \cdot 10^{-13}$ \\
\hline
\end{tabular}


The investigation of the electrical conductivity of pyrroles $\mathbf{2 b}, \mathbf{2 c}, \mathbf{4 d}$, and $\mathbf{6 e}$ has been undertaken (Table 3). Replacement of the fused cycloalkyl moiety by a thiophene substituent, that extends the conjugation chain (transition from the pyrrole $\mathbf{2 b}$ to the pyrrole $\mathbf{4 d}$ ), leads to an increase of electrical conductivity by one order of magnitude. The introduction of a phenyl substituent into the pyrrole molecule $(\mathbf{2 b})$ results in a considerable increase $\left(2.310^{-9} \mathrm{Cm} \cdot \mathrm{cm}^{-1}\right)$ in electrical conductivity, seemingly due to formation of intermolecular aggregates. ${ }^{2,14}$

\section{Experimental Section}

General Procedures. IR spectra (KBr pellets) were run on a IFS-25 spectrometer in the 400$4000 \mathrm{~cm}-1$ region. UV spectra were run on a Specord-Vis $75 .{ }^{1} \mathrm{H}$ NMR spectra were recorded on a Bruker DPX-250 spectrometer (250.1 MHz) using DMSO- $d_{6}$ (for compounds 2c, 4d,e, 5d,e, 6e, 8f) and $\mathrm{CHCl}_{3}$ (for compounds $\mathbf{2 a , b}, \mathbf{8 g}$ ) as solvents, hexamethyldisiloxane as internal standard. Recording of 2D spectra COSY and NOESY followed routine techniques. ${ }^{15,16}$ Mixing period selected for each sample was $1-1.4 \mathrm{sec}$.

Analysis of the reaction mixtures and purity controls were performed by TLC on Silufol UV-254 using $n$-hexane/diethyl ether 1:1 as eluent. Preparative separation was carried out by TLC on $\mathrm{Al}_{2} \mathrm{O}_{3}$ plates with diethyl ether as eluent.

The pyrrole starting materials $1 \mathbf{1 a}-\mathbf{c}, \mathbf{3 d}, \mathbf{e}$, and $\mathbf{7 g}$ were obtained from oximes and propyne-allene mixtures ${ }^{17}$ by the Trofimov reaction, ${ }^{6,7,18-20}$ pyrrole $\mathbf{7 f}$ was obtained from pyrrole $\mathbf{2 b}$ and acetylene by the Trofimov reaction. ${ }^{21}$

$A b$ initio calculations $\left(\mathrm{HF} / 6-31 \mathrm{G}^{*}\right)$ of geometry, total energy, dipole moments and distribution of full charges of some conformers were accomplished using the Gaussian 98 program package. ${ }^{22}$

Specific electrical conductivity was measured by the two-electrode method using an E6-13A teraohmmeter and VK-2-16 electrometric amplifier. Voltage was supplied by a B5-50 direct current source. Photosensitive layers were prepared using PVCz with MM 5000-8000. The preparation procedure was described earlier. ${ }^{23}$ The electrophotographic sensitivity of layers (3$3.5 \mu \mathrm{m}$ thick), dried in vacuum beforehand, the charging potential and time of potential dark drop were examined at positive and negative potentials induced on the photo sensitized surface by means of a "Skorotron" discharger. $\mathrm{S}_{0.5}$ and $\tau_{0.5}$ were calculated by half-drop value induced on the potential surface. The device to measure electrophotographic characteristics has been described in detail. ${ }^{24}$

2-Methyl-1-vinyl-4,5,6,7-tetrahydroindole (7f). By the method described earlier ${ }^{21}$ the reaction of pyrrole $\mathbf{2 b}$ and acetylene at $115-125^{\circ} \mathrm{C}$ for $2 \mathrm{~h}$ afforded $7 \mathbf{f}(49 \%$, purity $95 \%)$ as a lightyellow fluid, bp $105^{\circ} \mathrm{C} / 6 \mathrm{~mm} \mathrm{Hg} ; n$ 1.5534. IR (neat, $\mathrm{cm}^{-1}$ ): 3123, 3087, 3049, 2972, 2969 , 2930, 2843, 1642, 1600, 1535, 1429, 1396, 1382, 1347, 1328, 1290, 1254, 1238, 1205, 1154, $1101,1074,1058,1034,993,968,938,858,779,724,693,639,604,580 ;{ }^{1} \mathrm{H}$ NMR: $\delta 6.72(1 \mathrm{H}$, $\mathrm{dd}, J=16.3,9.6 \mathrm{~Hz}, \mathrm{CH}=) ; 5.70(1 \mathrm{H}, \mathrm{s}, \mathrm{H}-3) ; 4.97\left(1 \mathrm{H}, \mathrm{d}, J=16.3 \mathrm{~Hz},=\mathrm{CH}_{\mathrm{b}}\right) ; 4.75(1 \mathrm{H}, J=9.6$ 
$\left.\mathrm{Hz},=\mathrm{CH}_{\mathrm{a}}\right) ; 2.25(\mathrm{~s}, 3 \mathrm{H}, \mathrm{Me}) ; 2.61\left(2 \mathrm{H}, \mathrm{m}, \mathrm{CH}_{2}-7\right) ; 2.44\left(2 \mathrm{H}, \mathrm{m}, \mathrm{CH}_{2}-4\right) ; 1.81\left(2 \mathrm{H}, \mathrm{m}, \mathrm{CH}_{2}-6\right)$; $1.75\left(2 \mathrm{H}, \mathrm{m}, \mathrm{CH}_{2}-5\right)$. Anal. Calcd. for $\mathrm{C}_{11} \mathrm{H}_{15} \mathrm{~N}$ (161.12): $\mathrm{C} 81.94 ; \mathrm{H} 9.38 ; \mathrm{N}$ 9.69. Found $\mathrm{C}$ 81.60, H 9.51, N 9.44.

Reaction of pyrroles 1a-c, 3d,e, 7f,g with TCNE (general procedure). A solution of pyrrole (1 mmol) and TCNE (1 mmol, $128 \mathrm{mg})$ in DMSO $(20 \mathrm{~mL})$ was allowed to stand at room temperature for $30 \mathrm{~min}$, then poured into of cold water $(100 \mathrm{~mL})$. The precipitated crystals were filtered off, dried and purified by thin layer chromatography.

3-(1,2,2-Tricyanovinyl)-2,4,5-trimethyl-pyrrole (2a). Dark-cherry colored crystals (179 mg, $85 \%) ; \mathrm{mp} 152{ }^{\circ} \mathrm{C}$. IR $\left(\mathrm{KBr}, \mathrm{cm}^{-1}\right): 3351,2943,2868,2285,2221,1610,1522,1460,1427,1384$, 1370, 1321, 1267, 1201, 1132, 1047, 993, 699, 626, 565, 532, 473, 417; ${ }^{1} \mathrm{H}$ NMR: $\delta 8.20(1 \mathrm{H}$, br $\mathrm{s}, \mathrm{NH}) ; 2.37(3 \mathrm{H}, \mathrm{s}, \mathrm{Me}-5) ; 2.17(3 \mathrm{H}, \mathrm{s}, \mathrm{Me}-4) ; 2.11(3 \mathrm{H}, \mathrm{s}, \mathrm{Me}-2)$. Anal. Calcd. for $\mathrm{C}_{12} \mathrm{H}_{10} \mathrm{~N}_{4}$ (210.17): C, 68.56; H, 4.79; N, 26.65. Found: C, 68.72; H, 4.66; N, 26.18.

3-(1,2,2-Tricyanovinyl)-2-methyl-4,5,6,7-tetrahydroindole (2b). Dark cherry-colored crystals (203 mg, 86\%); mp $210{ }^{\circ} \mathrm{C}$. IR (KBr, cm $\left.{ }^{-1}\right): 3319,3223,3127,2941,2852,2229,1615,1531$, 1458, 1427, 1380, 1364, 1327, 1314, 1270, 1256, 1239, 1201, 1156, 1127, 1030, 1003, 712, 703, 683, 632, 569, 529, 452; ${ }^{1} \mathrm{H}$ NMR: $\delta 8.30\left(1 \mathrm{H}\right.$, br s, NH); $2.53\left(4 \mathrm{H}, \mathrm{m}, \mathrm{CH}_{2}-4,7\right) ; 2.38(3 \mathrm{H}, \mathrm{s}$, Me); 1.78 (4H, m, $\left.\mathrm{CH}_{2}-5,6\right)$. Anal. Calcd. for $\mathrm{C}_{14} \mathrm{H}_{12} \mathrm{~N}_{4}$ (236.28): C, 71.17; H, 5.12; N, 23.71 . Found: C, 70.94; H, 5.36; N, 23.41.

3-(1,2,2-Tricyanovinyl)-2-methyl-5-phenylpyrrole (2c). Dark cherry-colored crystals (243 mg, 94\%); mp 241-242 ${ }^{\circ} \mathrm{C}$. IR ( $\left.\mathrm{KBr}, \mathrm{cm}^{-1}\right): 3304,2960,2217,1610,1592,1572,1528,1500,1487$, 1435, 1400, 1370, 1294, 1257, 1200, 1145, 1074, 1021, 997, 950, 928, 817, 765, 700, 688, 649, 550, 539, 498; ${ }^{1} \mathrm{H}$ NMR: $\delta 12.71(1 \mathrm{H}$, br s, NH); 7.63, 7.46, $7.34(5 \mathrm{H}, \mathrm{m}, \mathrm{Ph}) ; 7.20$ (1H, s, H-4); $2.65(3 \mathrm{H}, \mathrm{s}, \mathrm{Me})$. Anal. Calcd. for $\mathrm{C}_{16} \mathrm{H}_{10} \mathrm{~N}_{4}$ (258.21): C, 74.42; H, 3.88; N, 21.69. Found: C, 73.92; H, 3.66; N, 21.08.

3-(1,2,2-Tricyanovinyl)-2-methyl-5-(2-thienyl)pyrrole (4d). Black-blue crystals (198, 75\%); $\mathrm{mp} 240{ }^{\circ} \mathrm{C}$. IR (KBr, cm $\left.{ }^{-1}\right) 3284,2924,2222,1612,1532,1510,1484,1440,1404,1370,1288$, 1279, 1220, 1193, 1144, 1068, 1057, 1035, 999, 899, 844, 836, 790, 713, 702, 550, 537, 496, 470; ${ }^{1} \mathrm{H}$ NMR: $\delta 12.87(1 \mathrm{H}$, br s, NH); $7.56(1 \mathrm{H}, \mathrm{dd}, J=5.0,1.0 \mathrm{~Hz}, \mathrm{H}-5$ of thiophene); 7.41 $(1 \mathrm{H}, \mathrm{dd}, J=3.6,1.0 \mathrm{~Hz}, \mathrm{H}-3$ of thiophene); $7.13(1 \mathrm{H}, \mathrm{dd}, J=5.0$ Гц, $3.6 \mathrm{~Hz}, \mathrm{H}-4$ of thiophene); $7.00(1 \mathrm{H}, \mathrm{s}, \mathrm{H}-4) ; 2.64(3 \mathrm{H}, \mathrm{s}, \mathrm{Me})$. Anal. Calcd. for $\mathrm{C}_{14} \mathrm{H}_{8} \mathrm{~N}_{4} \mathrm{~S}(264.30): \mathrm{C} 63.62 ; \mathrm{H} \mathrm{3.05}$; N 21.20; S, 12.13. Found C 63.17; H 2.89; N 20.75; S 11.64.

4-(1,2,2-Tricyanovinyl)-2-methyl-5-(2-thienyl)pyrrole (5d). Black-blue crystals (40 mg, 15\%); mp $180^{\circ} \mathrm{C}$. IR (KBr, cm $\left.{ }^{-1}\right) 3266,3108,2927,2853,2227,1634,1603,1508,1470,1437,1411$, $1369,1273,1231,1221,982,940,846,796,730,719,555,532 ;{ }^{1} \mathrm{H}$ NMR: $\delta 12.38(1 \mathrm{H}$, br s, $\mathrm{NH}) ; 7.85(1 \mathrm{H}, \mathrm{dd}, J=4.8,1.0 \mathrm{~Hz}, \mathrm{H}-5$ of thiophene $) ; .43(1 \mathrm{H}, \mathrm{dd}, J=3.6,1.0 \mathrm{~Hz}, \mathrm{H}-3$ of thiophene); $7.21(1 \mathrm{H}, \mathrm{dd}, J=4.8,3.6 \mathrm{~Hz}, \mathrm{H}-4$ of thiophene); $6.64(1 \mathrm{H}, \mathrm{s}, \mathrm{H}-3) ; 2.25(3 \mathrm{H}, \mathrm{s}, \mathrm{Me})$. Anal. Calcd. for $\mathrm{C}_{14} \mathrm{H}_{8} \mathrm{~N}_{4} \mathrm{~S}$ (264.30): C 63.62; H 3.05; N 21.20; S 12.13. Found C 63.15; H 2.86; N 20.78; S 11.83 .

4-(1,2,2-Tricyanovinyl)-2-(2-furyl)-5-methylpyrrole (4e). Black-blue crystals (45 mg, 18\%); 
mp $230^{\circ} \mathrm{C}$. IR (KBr, cm $\left.{ }^{-1}\right)$ 3291, 3192, 2923, 2853, 2213, 1642, 1554, 1524, 1494, 1480, 1462 , 1422, 1376, 1344, 1279, 1221, 1193, 1134, 1002, 961, 796, 727, 592; ${ }^{1} \mathrm{H}$ NMR: $\delta 12.92(1 \mathrm{H}$, br $\mathrm{s}, \mathrm{NH}) ; 7.77(1 \mathrm{H}, \mathrm{d}, J=1.6 \mathrm{~Hz}, \mathrm{H}-5$ of furan $) ; .08(1 \mathrm{H}, \mathrm{s}, \mathrm{H}-4) ; 6.80(1 \mathrm{H}, \mathrm{d}, J=3.3 \mathrm{~Hz}, \mathrm{H}-3$ of furan); $6.62(1 \mathrm{H}, \mathrm{dd}, J=3.3,1.6 \mathrm{~Hz}, \mathrm{H}-4$ of furan $) ; 2.65(3 \mathrm{H}, \mathrm{s}, \mathrm{Me})$. Anal. Calcd. for $\mathrm{C}_{14} \mathrm{H}_{8} \mathrm{~N}_{4} \mathrm{O}$ (248.25): C 67.74; H 3.25; N 22.57. Found C 67.47; H 2.98; N 22.08.

3-(1,2,2-Tricyanovinyl)-2-(2-furyl)-5-methylpyrrole (5e). Black-blue crystals (22 mg, 9\%); $\mathrm{mp} 130^{\circ} \mathrm{C}$. IR (KBr, cm $\left.{ }^{-1}\right)$ 3289, 2956, 2923, 2853, 2213, 1642, 1633, 1554, 1524, 1496, 1480, $1462,1422,1368,1344,1279,1221,1193,1134,1001,961,795,740,725,592 ;{ }^{1} \mathrm{H}$ NMR: $\delta$ $12.17(1 \mathrm{H}$, br s, NH); $7.68(1 \mathrm{H}, \mathrm{d}, J=1.5 \mathrm{~Hz}, \mathrm{H}-5$ of furan $) ; 6.65(1 \mathrm{H}, \mathrm{d}, J=3.2 \mathrm{~Hz}, \mathrm{H}-3$ of furan); $6.62(1 \mathrm{H}, \mathrm{s}, \mathrm{H}-3) ; 6.56(1 \mathrm{H}, \mathrm{dd}, J=3.2,1.5 \mathrm{~Hz}, \mathrm{H}-4$ of furan); 2.38 (3H, s, Me). Anal. Calcd. for $\mathrm{C}_{14} \mathrm{H}_{8} \mathrm{~N}_{4} \mathrm{O}$ (248.25): C 67.74; H 3.25; N 22.57. Found C 67.32; H 3.06; N 22.17.

2-[2-Furyl-5-(5-methyl-1H-pyrrol-2-yl)]ethylene-1,1,2-tricarbonitrile (6e). Black-blue crystals (142 mg, 57\%); mp $240{ }^{\circ} \mathrm{C}$. IR $\left(\mathrm{KBr}, \mathrm{cm}^{-1}\right) 3336,3118,2922,2212,1615,1560,1514$, $1474,1365,1345,1310,1270,1199,1105,1087,1042,980,963,848,791,540,520 ;{ }^{1} \mathrm{H}$ NMR: $\delta 12.16(1 \mathrm{H}$, br s, NH); $7.83(1 \mathrm{H}, \mathrm{d}, J=4.4 \mathrm{~Hz}, \mathrm{H}-4$ of furan $) ; .11(1 \mathrm{H}, \mathrm{d}, J=4.4 \mathrm{~Hz}, \mathrm{H}-3$ of furan); $6.80(1 \mathrm{H}, \mathrm{m}, \mathrm{H}-4) ; 6.18(1 \mathrm{H}, \mathrm{m}, \mathrm{H}-3) ; 2.35(3 \mathrm{H}, \mathrm{s}, \mathrm{Me})$. Anal. Calcd. for $\mathrm{C}_{14} \mathrm{H}_{8} \mathrm{~N}_{4} \mathrm{O}$ (248.25): C 67.74; H 3.25; N 22.57. Found C 67.22; H 3.36; N 22.28.

3-(1,2,2-Tricyanovinyl)-2-methyl-1-vinyl-4,5,6,7-tetrahydroindole (8f). Dark-cherry crystals (241 mg, 92\%); mp $132{ }^{\circ} \mathrm{C}$. IR $\left(\mathrm{KBr}, \mathrm{cm}^{-1}\right)$ 2928, 2860, 2222, 1644, 1525, 1506, 1452, 1440, $1415,1401,1385,1369,1333,1255,1242,1160,1113,1067,964,906,617,580,556 ;{ }^{1} \mathrm{H}$ NMR: $\delta 6.95(1 \mathrm{H}, \mathrm{dd}, J=9.4,15.5 \mathrm{~Hz}, \mathrm{CH}=) ; 5.41\left(1 \mathrm{H}, \mathrm{d}, J=15.5 \mathrm{~Hz},=\mathrm{CH}_{\mathrm{b}}\right) ; 5.39(1 \mathrm{H}, \mathrm{d}, J=9.4 \mathrm{~Hz}$, $\left.=\mathrm{CH}_{\mathrm{a}}\right) ; 2.54\left(4 \mathrm{H}, \mathrm{m}, \mathrm{CH}_{2}-4,7\right) ; 2.33(3 \mathrm{H}, \mathrm{s}, \mathrm{Me}) ; 1.71\left(4 \mathrm{H}, \mathrm{m}, \mathrm{CH}_{2}-5,6\right)$. Anal. Calcd. for $\mathrm{C}_{16} \mathrm{H}_{14} \mathrm{~N}_{4}$ (262.31): C 73.28; H 5.34; N 21.37. Found C 73.54; H 5.46; N 20.87.

3-(1,2,2-Tricyanovinyl)-1-isopropenyl-2-methyl-4,5,6,7-tetrahydroindole (8g). Dark-cherry crystals (251 mg, 91\%); mp 149-150 ${ }^{\circ} \mathrm{C}$. IR $\left(\mathrm{KBr}, \mathrm{cm}^{-1}\right) 3114,2957,2922,2851,2229,1666$, 1522, 1491, 1458, 1443, 1415, 1396, 1332, 1302, 1239, 1194, 1161, 1133, 1069, 1031, 1011, 957, 921, 909, 654, 551; ${ }^{1} \mathrm{H}$ NMR: $\delta 5.43\left(1 \mathrm{H}, \mathrm{q}, J=1.44 \mathrm{~Hz}, \mathrm{H}_{\alpha}\right) ; 5.04\left(1 \mathrm{H}, \mathrm{q}, J=0.6 \mathrm{~Hz}, \mathrm{H}_{\beta}\right)$; $2.57\left(2 \mathrm{H}, \mathrm{m}, \mathrm{CH}_{2}-4\right) ; 2.43\left(2 \mathrm{H}, \mathrm{m}, \mathrm{CH}_{2}-7\right) ; 2.27$ (3H, s, Me); 2.00 (3H, dd, J=1.4, $0.6 \mathrm{~Hz}, \mathrm{CH}_{3}-$ $\mathrm{CH})$; $1.76\left(4 \mathrm{H}, \mathrm{m}, \mathrm{CH}_{2}-5,6\right)$. Anal. Calcd. for $\mathrm{C}_{17} \mathrm{H}_{16} \mathrm{~N}_{4}$ (276.34): C 73.91; H 5.80; N 20.29. Found C 74.24; H 5.66; N 20.66.

\section{References}

1. Sausen, G. N.; Engelhardt, V. A.; Middleton, W. J. J. Am. Chem. Soc. 1958, 80, 2815.

2. Vokin, A. I.; Vakul'skaya, T. I.; Murzina, N. M.; Demenev, A. P.; Sobenina, L. N.; Mikhaleva, A. I.; Trofimov, B. A. Zh. Org. Khim. 2000, 36, 1539.

3. Bonnett, R.; White, J. D. J. Chem. Soc. 1963, 3, 1648.

4. Belen'kii, L. I. Khim. Geterotsikl. Soed. 1980, 12, 1587.

5. Trofimov, B. A.; Korostova, S. E.; Mikhaleva, A. I.; Hesterenko, R. N.; Sigalov, M. V.; 
Voronov, V. K.; Polovnikova, R. I. Zh. Org. Khim. 1982, 18, 894; Chem. Abstr. 1982, 97, 55630 .

6. Trofimov, B. A.; Mikhaleva, A. I. N-Vinylpirroly ( $N$-Vinylpyrroles); Nayka: Novosibirsk, 1984; pp 1-264; Chem. Abstr. 1985, 102, 203864.

7. Trofimov, B. A. Vinylpyrroles, In Pyrroles. Part Two. The Synthesis, Reactivity, and Physical Properties of Substituted Pyrroles. R. A. Jones, Ed.. Interscience Publication, Wiley: New-York, 1992; p. 131.

8. Gorshkov, A. G.; Turchaninov, V. K.; Kurov, G. N.; Skvortsova, G. G. Zh. Org. Khim. 1979, 15, 767; Chem. Abstr. 1979, 91, 91575.

9. Gorshkov, A. G.; Domnina, E. S.; Turchaninov, V. K.; Larin, M. F.; Skvortsova, G. G. Khim. Geterotsikl. Soed. 1983, 7, 951; Chem. Abstr. 1983, 99, 139690.

10. Gorshkov, A. G.; Domnina, E. S.; Mikhaleva, A. I.; Skvortsova, G. G. Khim. Geterotsikl. Soed. 1985, 6, 848; Chem. Abstr. 1985, 102, 203833.

11. Chetkina, L. A.; Zavodnik, V. E.; Il'ina, I. G. Crystallgrafiya. 1983, 28, 699. Chem. Abstr. 1983, 99, 149917.

12. Turchaninov, V. K.; Vokin, A. I.; Korostova, S. E. Iz. RAN. Ser. Khim. 1997, 8, 1472; Chem. Abstr. 1998, 128, 34415.

13. Brock, C. P.; Minton, R. P. J. Am. Chem. Soc. 1989, 111, 4586.

14. Sasaki, A.; Aihara, J.; Matsunaga, J. Bull. Chem. Soc. Japan 1974, 47, 2926.

15. Kumar, A.; Nagayama, K.; Ernst, R. R. J. Magn. Reson. 1980, 40, 321.

16. Jeener, J.; Meier, B. H.; Ernst, R. R. J. Chem. Phys. 1979, 69, 4546.

17. Trofimov, B. A.; Tarasova, O. A.; Mikhaleva, A. I.; Kalinina, N. A.; Sinegovskaya, L. M.; Henkelman, J. Synthesis 2000, 11, p. 1585.

18. Trofimov, B. A. Preparation of Pyrroles from Ketoximes and Acetylene, In Adv. Heterocycl. Chem. A. R. Katritzky, Ed. Academic Press, Inc.: San Diego, 1990; Vol. 51, p. 177.

19. Tedeschi R. J. In Encyclopedia of Physical Science and Technology, Academic Press, Inc.: San Diego, 1992; Vol 1, p. 27.

20. Bean G. P. The synthesis of 1H-Pyrroles, In: Pyrroles. Part One. The Synthesis and the Chemical and the Physical Aspects Pyrrole Ring, R. A. Jones, Ed. Interscience Publication, Wiley: New York, 1992; p. 105.

21. Tarasova, O. A.; Mal'kina, A. G.; Mikhaleva, A. I.; Brandsma, L.; Trofimov, B. A. Synthetic. Commun. 1994, 24, 2035.

22. Gaussian 98, Revision A.6, Gaussian, Inc., Pittsburgh PA, 1998.

23. Patent RU 2008307 1994; Chem. Abstr. 1995, 123, 301476.

24. Smirnov, V. I.; Vasilevskij, S. F.; Eskova, L. A.; Domnina, E. S.; Nikitin, M. V.; Babushkin, V. A.; Shcherbakov, V. V.; Shvartsberg, M. S. Patent SU 1786031 1993; Chem. Abstr. 1994, 120, 65846. 